\title{
STUDY ON CONTROLLER WITH ONLINE DECISION SUPPORT SYSTEM FOR LASER- CONTROLLED LEVELING
}

\author{
Yongsheng $\mathrm{Si}^{1}$, Gang Liu ${ }^{2}$, Yuliang Chen ${ }^{1}$ \\ 1 Hebei Agricultural University, 071001, Baoding, China siyongsheng@yahoo.com \\ 2China Agricultural University, 100083,Beijing, China pac@cau.edu.cn
}

Abstract: A controller and its hardware structure for laser-controlled field leveling was developed that has online decision support function. S3C44B0X and $\mu \mathrm{C} / \mathrm{OS}-\mathrm{II}$ were adopted as the CPU and operating system respectively. The controller has three main functions: course determination, rough/precision leveling switch and earthwork calculation. The purpose of course determination is to find the shortest transport distance and minimize the cost. The rough/precision leveling switch can increase working efficiency and reduce the wearing and tearing of the equipments. And the function of earthwork calculation is used to estimate the workload of the leveling system. Experiments showed that the online support system made the field leveling quite efficient and intelligent.

Key words: decision support system, laser leveling, ARM, $\mu \mathrm{C} / \mathrm{OS}-\mathrm{II}$, controller -

\section{INTRODUCTION}

Laser leveling is an important technique widely used in many fields of industry and agriculture. It provides precise measurement for horizontal, vertical, aligning or measuring in different applications. In agriculture, this technique is effectively used to improve the irrigation quality and planting conditions that can save water and increase yields.

In this paper, the laser leveling system consists of five parts: laser transmitter, laser receiver, controller, hydraulic device and bucket. The operation principle of the system is as follows: Laser transmitter is fixed at the building site with tripod, and it can automatically rotate to form 
horizontal laser plane as a reference to land leveling above the field. The laser receiver is installed on the backstay of the bucket. Thus, the height of the field can be measured and the signals can be sent to controller. After receiving the signals, the controller will adjust the height of the bucket through the hydraulic device.(Figure 1)

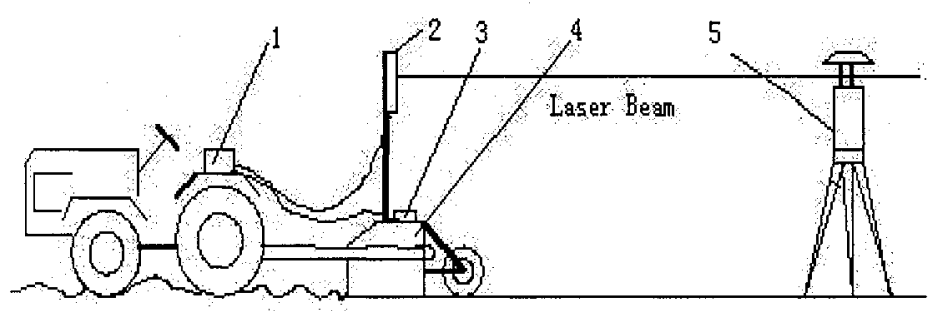

1 controller 2 receiver 3 hydraulic device 4 bucket 5 transmitter

Figure I Schematic diagram of the laser leveling system

Many laser leveling systems have been developed in China, For example, China Agricultural University (CAU) developed a laser leveling sample device in 2002. All laser leveling systems can work efficiently with the help of experienced operators. The operators need to draw a 'cut/fill' map and make a plan to effectively move soil from high to low areas. The operators also need to measure distance of the field as many of the critical decisions are based on the accuracy of distance. The workload can be estimate by calculating the volume of soil to be moved. To make the laser leveling system more efficient and more intelligent, a controller with online decision support system was developed based on the laser leveling sample device designed by Research Center for Precision Agriculture, China Agricultural University (CAU). The online decision support system has four main functions:

1. Automatically record the height of the field with the GPS data

2. Calculate the mean height of the field and determine a course to effectively move soil from high to low areas

3. Calculate the volume of soil shifted

4. Switch Rough/Precision leveling

\section{HARDWARE STRUCTURE}

The key step for the system design is to choose CPU. Considering the requirements for agriculture and low-cost, the CPU should have some important features such as integrated LCD controller, high clock rate, etc. In 
recent years, the ARM (Advanced RISC Machines) is popularly used as embedded processor because it is a high-capability and low-cost RISC microprocessor. The SAMSUNG Company provides a kind of ARM processor: s3c44b0x. It is a 16/32-bit RISC microprocessor with LCD controller and $66 \mathrm{MHZ}$ clock rate. The LCD controller has 256-color DSTN with 1-ch LCD dedicated DMA. In addition, the s3c44b0x has 2-ch UART that can be used to receive the GPS signals. The system architecture is shown in detail in Figure 2.

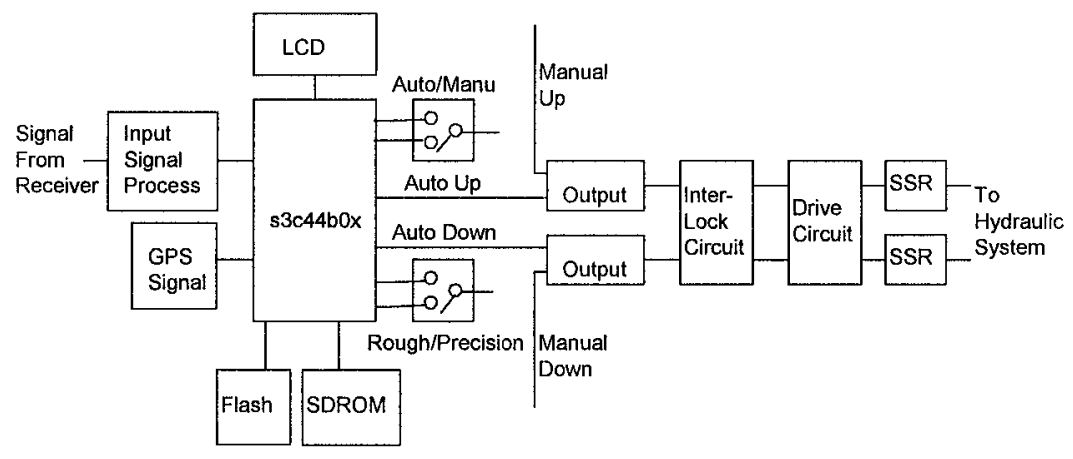

Figure 2 System Architecture

\section{ONLINE DECISION SUPPORT SYSTEM}

The online decision support system is developed based on $\mu \mathrm{C} / \mathrm{OS}-\mathrm{II}$ operating system. It has three main functions: course determination, rough/precision leveling switch, and earthwork calculation. The online decision support system can receive the GPS and field height data from the controller in real-time. By analyzing the data, the system will output the optimal course scheme, calculate workload and automatically adjust the leveling.

\subsection{Course Determination Based on Quadtrees Environment Model}

Transportation distance is one of the key factors that affect total budget of field leveling project. The cost of field leveling project is calculated as (Liu Changshun, Liu Gang, 2004):

$$
C=\frac{W a}{P} \square F=\frac{V \square \bar{D}}{P} \square F
$$


where $W a$ represents the work done in field leveling, $\mathrm{P}$ is the power, $\mathrm{F}$ is the fee per unit time, $\mathrm{V}$ is the volume of soil to be moved and $\bar{D}$ is the transport distance. $\mathrm{P}$ and $\mathrm{F}$ will be changed to constant values after a period of time. And then, the cost is determined by $V \bar{D} \bar{D}$. In some field conditions, $V$ is a constant. If so, the cost is determined by $\bar{D}$. The purpose of course determination is to find the shortest transport distance and to minimize the cost. Hence, the tractor should be driven in a circular or elliptical direction from the high areas to the nearest lower areas in the field. And the minimal turn-around radius of the tractor should also be considered. The optimal course will be displayed in the LCD to guide the operator to control the tractor.

To achieve this function, a grid map is created to visually represent the field information that includes the field height data and GPS data. To calculate the mean height, all of the measured points are added up and divided by the number of measurements. Similarly, the height of each grid can be calculated. Then all the data are input into the controller. To improve operational efficiency, an intelligent measurement device for field topographic survey was developed by China Agricultural University (Liu Zhichun, 2004). The height data and GPS data are stored in quadtrees structure. In the course determination, environment model of the leveling system is square area consisting of $2 \times 2$ basic elements (Figure. 3 ). The basic elements are also squares of which the length of the side should be longer than the width of bucket and the minimal turn-around radius of tractor. The value of the basic elements can be 0,1 or 2 which indicates the height of the grid is lower than, equal to, or higher than the reference height respectively. The reference height for the rough leveling mode is different from that for the precision mode. If the heights in one grid are all higher or all lower than the reference height, this grid does not need to be divided and should be marked with 2 or 0 . If some of the recorded heights in one grid are higher than the reference height while the others are lower, this grid should be divided into 4_subspaces. Divide the subspace by the same principle. Generally, the grids marked with 2 are named 'cut grid' and the grids marked with 1 are named 'fill grid'. The first two highest and lowest areas will be displayed on LCD with the guide course (Figure 4). The height data will be updated while the system is working.

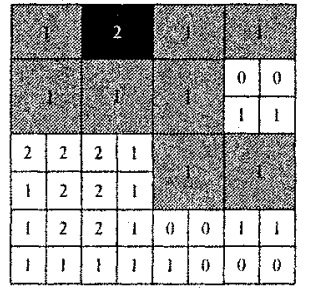

Figure 3 Environment Model

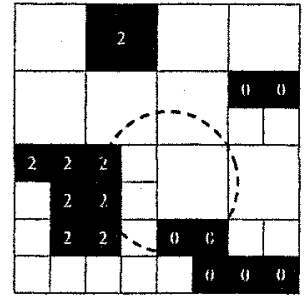

Figure 4 Course Displayed on LCD 


\subsection{Rough/Precision Leveling}

The rough/precision leveling switch function of the online decision support system is to increase working efficiency and reduce the wearing and tearing of the equipments. Two leveling modes (rough and precision) are used to switch during the processing of operation. Generally, the rough leveling mode is used in the beginning. First, the field height data are collected by the laser receiver and translated to controller. Then, the online decision support system outputs the signals to the controller. When all the data inputted are distributed within certain area, the system will indicate on the control panel that the operator should switch leveling mode to precision leveling. At the same time, the system outputs different signals according to the rising/falling speed of the bucket, the switch frequency of the valve, the rotating speed of the laser transmitter. The output signals are different in different modes.

There are nine kinds of input signals accepted and processed from the receiver that indicate different positions of the bucket. The controller will output corresponding signals according to input signals and rough/precision leveling mode. Moreover, the controller has memory function. It can judge the position of the bucket when the laser beam above or below the receiver and adjust the bucket accordingly. (Table 1)

Table 1. Input and output signals

\begin{tabular}{llllll}
\hline \multirow{2}{*}{$\begin{array}{l}\text { Input } \\
\text { Signals }\end{array}$} & $\begin{array}{l}\text { Elevation } \\
\text { Indicated }\end{array}$ & \multicolumn{4}{l}{ Output Signals (positive pulse in 200ms period) } \\
\cline { 3 - 6 } & & $\begin{array}{l}\text { Precision Leveling } \\
\text { Channel 1 }\end{array}$ & $\begin{array}{l}\text { Channel } 2 \\
\text { (down) }\end{array}$ & $\begin{array}{l}\text { Channel 1 } \\
\text { (up) }\end{array}$ & $\begin{array}{l}\text { Channel 2 } \\
\text { (down) }\end{array}$ \\
\hline 10000 & very high & $200 \mathrm{~ms}$ & $0 \mathrm{~ms}$ & $200 \mathrm{~ms}$ & $0 \mathrm{~ms}$ \\
11000 & very high & $200 \mathrm{~ms}$ & $0 \mathrm{~ms}$ & & \\
01000 & high & $80 \mathrm{~ms}$ & $0 \mathrm{~ms}$ & & \\
\hline & & Output Signals (positive pulse in 200ms period) & \\
01100 & high & $80 \mathrm{~ms}$ & $0 \mathrm{~ms}$ & $0 \mathrm{~ms}$ & $0 \mathrm{~ms}$ \\
00100 & even & $0 \mathrm{~ms}$ & $0 \mathrm{~ms}$ & & $200 \mathrm{~ms}$ \\
00110 & low & $0 \mathrm{~ms}$ & $80 \mathrm{~ms}$ & & \\
00010 & low & $0 \mathrm{~ms}$ & $80 \mathrm{~ms}$ & $0 \mathrm{~ms}$ & \\
00011 & very low & $0 \mathrm{~ms}$ & $200 \mathrm{~ms}$ & & \\
00001 & very low & $0 \mathrm{~ms}$ & $200 \mathrm{~ms}$ & & \\
\hline
\end{tabular}




\subsection{Earthwork Calculation}

There are different ways to calculate the earthwork. Square grid is a common method to estimate the quantity of earthwork (Wang Yujuan, Chen lijuan, 1995). Two algorithms are used to calculate the mean height: weighting average algorithm and arithmetic average algorithm. The former is higher in precision (Lin Weiqi, 2001) and was adopted in the support system. The volume of soil to be cut or filled in the grid can be calculated as (Li Fuxiang, et al., 2000):

$$
\begin{aligned}
V_{C i} & =\frac{A_{i}\left[\sum C(x, y)\right]^{2}}{4\left[\left\{\left|\sum C(x, y)\right|+\left|\sum F(x, y)\right|\right\}\right.} \\
V_{F i} & =\frac{A_{i}\left[\sum F(x, y)\right]^{2}}{4\left\{\left\{\left|\sum C(x, y)\right|+\left|\sum F(x, y)\right|\right\}\right.}
\end{aligned}
$$

where $\mathrm{V}_{\mathrm{ci}}$ and $\mathrm{V}_{\mathrm{Fi}}$ represent the volume of soil to be cut or filled in the grid, respectively. $C(x, y)$ and $F(x, y)$ indicate the heights need to be cut or filled at the 4 corners of the grid. $A_{i}$ is the area of the grid.

\section{EXPERIMENT RESULTS}

Experiments have been conducted in Beijing Xiaotangshan Precision Agriculture Demonstration Base to check if the online support system can work normally. There are two parameters to evaluate the quality of field leveling. One is $\mathrm{s}_{\mathrm{d}}$ (standard deviation):

$$
S_{d}=\sqrt{\sum_{i=1}^{n}\left(h_{i}-\bar{h}\right)^{2} /(n-1)}
$$

where hi represents the $\mathrm{i}^{\text {th }}$ height measured, $\bar{h}$ is the mean height and $\mathrm{n}$ is the number measured. The other parameter is $\mathrm{P}$ (percentage) 


$$
P=n_{c} / n
$$

where $n_{\mathfrak{c}}$ represents the number of points whose absolute difference, between the measured height and the mean height, is less than a certain value. The results of the experiments are shown in Table 2.

Table 2. Results of the two experiments

\begin{tabular}{lllll}
\hline & $\begin{array}{l}\text { Efficiency } \\
\text { (ha/h) }\end{array}$ & $\begin{array}{l}\mathrm{S}_{\mathrm{d}} \text { (before) } \\
(\mathrm{cm})\end{array}$ & $\begin{array}{l}\mathrm{S}_{\mathrm{d}}(\mathrm{after}) \\
(\mathrm{cm})\end{array}$ & $\mathrm{P}$ \\
(value=1.5cm) & 7.0 & 2.4 & 0.81 \\
No support system & 0.16 & 7.0 & 2.1 & 0.85 \\
With support system & 0.18 & 7.1 & & \\
\hline
\end{tabular}

Figure 5 and 6 are the figures drawn by the software SUFER based on the data before and after the leveling. From the two figures we can see that the use of online support system resulted in better leveling quality.
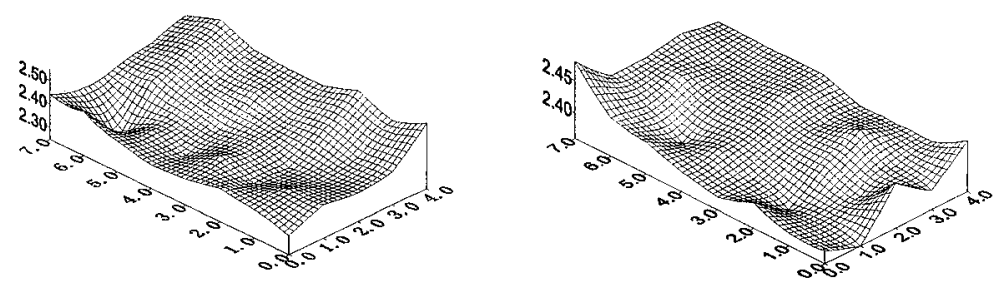

Figure 5 Before and after leveling without support system
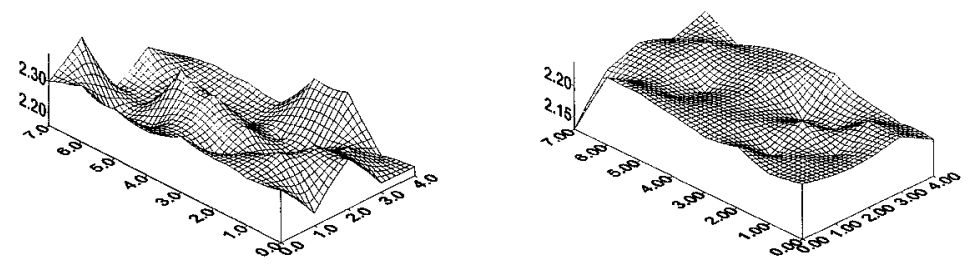

Figure 6 Before and after leveling with support system

\section{CONCLUSIONS}

Two experiments were conducted by the same operator. The results clearly showed that both the working efficiency and the leveling quality were improved by the online decision support system. To make the prototype more credible for users, it is necessary to work for long period to check and improve its stability and reliability. 


\section{ACKNOWLEDGEMENTS}

The research project is funded by the 863 Program "Research of Precise Irrigated Technique - Research and Development of Laser Leveling System" (2002AA6Z3041).

\section{REFERENCES}

[1] Liu Zhichun, Liu Gang, An Intelligent measurement system of the field landscape for laserleveling, 2004 CIGR International Conference,Beijng:III-195

[2] Wang Yujuan, Chenlijun, Computational Program for Earthwork Quantity with Square Grid, J. OF HLJ. Hydr. Eng. Col, NO.1 1995, 21 25

[3] Lin Weiqi, Method of measure and count and analysis on precision of earthwork, Southern Metals, 2001, 49 52

[4] Li Fuxiang, Xudi, Li Yinong, Effectiveness Evaluation and Application of Land Leveling Technology, Transactions of the Chinese Society of agricultural Engineering, 2002, 50 53 